\title{
GAIA Level 2 Non-reassuring Fetal Status
}

National Cancer Institute

\section{Source}

National Cancer Institute. GAIA Level 2 Non-reassuring Fetal Status. NCI Thesaurus.

Code C127995.

GAIA Level 2 Non-reassuring Fetal Status is defined by the presence of at least one of the following two criteria: first, a category III fetal heart rate tracing detected via continuous cardiotocography as defined by NICHD; second, one of the following two conditions must be met: a) an absent baseline fetal heart rate variability AND any of the following: recurrent late decelerations, recurrent variable deceleration, bradycardia (less than 110 bpm); OR b) a sinusoidal pattern. 